\title{
Annoyance responses to stable and changing aircraft noise exposure
}

\author{
Mark Brink, ${ }^{\text {a) }}$ Katja E. Wirth, ${ }^{\text {b) }}$ and Christoph Schierz ${ }^{\mathrm{c})}$ \\ ETH Zurich, MTEC-ZOA Public and Organizational Health, CH-8092 Zurich, Switzerland
}

Georg Thomann ${ }^{\text {d) }}$

Empa Materials Science \& Technology, Acoustics Laboratory, CH-8600 Dübendorf, Switzerland

Georg Bauer ${ }^{\mathrm{e})}$

University of Zurich, Institute of Social and Preventive Medicine, CH-8001 Zurich, Switzerland

(Received 21 March 2008; revised 16 June 2008; accepted 29 July 2008)

\begin{abstract}
This article reports the two extensive aircraft noise annoyance surveys subsequently carried out among residents in the vicinity of Zurich Airport in 2001 and 2003 in order to update and validate existing exposure-effect relationships for aircraft noise and annoyance in Switzerland. Logistic and polynomial approximations of the exposure-annoyance relationships for both the years 2001 and 2003 are presented for the $L_{\mathrm{dn}}, L_{\mathrm{den}}$, and $L_{A, \text { eq24 }}$ noise metrics. The results confirm other recently published international research and provide further evidence that community annoyance due to aircraft noise has increased over the past decades. Between the two survey years, a considerable amount of early morning and late evening flight operations have been relocated to use an other runway than before; thus both the effects of a recent step decrease and recent step increase on the exposure-annoyance relationship could be investigated. Residents that experienced a step increase elicited a quite pronounced over-reaction of annoyance which correlated with the magnitude of the change. Two logistic regression models are provided to forecast the effects of changes in exposure during shoulder hours in the early morning and the late evening.
\end{abstract}

(C) 2008 Acoustical Society of America. [DOI: 10.1121/1.2977680]

PACS number(s): 43.50.Qp, 43.50.Lj [BSF]

Pages: 2930-2941

\section{INTRODUCTION}

In areas with day-night aircraft noise levels $\left(L_{\mathrm{dn}}\right)$ below $70 \mathrm{~dB}(\mathrm{~A})$, annoyance is among the most important health effects caused by aircraft noise (Berglund and Lindvall, 1995). A wealth of exposure-effect functions for noise annoyance has been established in the past decades, relating traffic noise exposure, including aircraft noise, to the percentage of highly annoyed persons (Fidell et al., 1991; Miedema and Vos, 1998; Schultz, 1978). Some of them are based on very large data sets, collected from different studies in various countries (Miedema and Vos, 1998), and for many years defined a sort of de facto standard for noise impact assessment for noise policy issues, e.g., within the scope of noise abatement in the European Union (European Commission, 2002). However, many of the original data sets with studies dating back as far as to the 1960s are by now to be considered outdated and may not any longer correctly reflect the relationship between noise metrics and annoyance measures. There is evidence that today, people are more sensitive toward aircraft noise than they were decades ago. Guski (2004) reanalyzed the data from the Miedema and Vos metaanalysis (1998) with respect to the year of the study and the

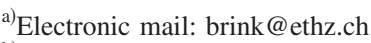

${ }^{b)}$ Electronic mail: katja.wirth@euresearch.ch

${ }^{c)}$ Electronic mail: cschierz@ethz.ch

${ }^{\mathrm{d})}$ Electronic mail: georg.thomann@empa.ch

${ }^{\text {e)}}$ Electronic mail: gfbauer@ ifspm.uzh.ch
}

respective $L_{\mathrm{dn}}$ for $25 \%$ highly annoyed (HA) persons and found that the exposure level needed to elicit a particular level of annoyance decreased considerably over the past decades. This trend has also been investigated and confirmed by van Kempen and van Kamp (2005) who added more recent studies to the data set. As could impressively be demonstrated in a recent multinational study (Babisch et al., 2007), the annoyance shift seems to be specific to aircraft noise: Whereas the so called "EU curve" (European Commission, 2002) for road traffic noise very well matches the exposure-effect relationships that can be found with new survey data, the EU curve for aircraft noise systematically underestimates the percentage of HA persons at any given exposure level. Concerning the reasons of this shift of the exposure-effect curve, several explanations are being currently discussed. On the one hand, in the past two decades, as Bröer and Wirth (Bröer, 2007; Bröer and Wirth, 2004) argued on the background of Beck's (1992) theory of risk society, aviation is no longer considered a sign of modernity and technical progress, and probably steadily lost its technological advancement appeal to its adverse effects such as noise and air pollution. On the other hand, the numbers of air traffic movements have doubled or tripled at many airports in the past decades, whereas the sound energy of single aircraft movements has consistently decreased, thus altering the trade-off between number of movements and total sound energy of all movements which might also lead to a change in the overall perception of aircraft noise and ultimately to an increase of annoyance. It has been reported as a result of the 
recently published ANASE study in the UK that the number of aircraft movements today better explains variance in annoyance than it did 20 years ago (Department for Transport, 2007). Further possible explanations for this trend, e.g., increasing public debate about the continuous expansion plans of airports, have been discussed in van Kempen and van Kamp (2005). In conclusion, in noise effect research, routinely updating the databases for establishing exposure-effect functions that provide a sound basis for noise impact assessment for current and future scenarios is a permanent necessity. When it comes to forecasting community response to aircraft noise after a (prospective) operational change (e.g., opening of a new runway), an additional source of uncertainty in the estimation of the degree of annoyance potentially comes into play, the so called over-reaction effect. The current study aims to tackle both these issues.

\section{A. Influence of a step change in exposure}

A typical application for exposure-effect functions that are derived from community surveys would be when public authorities must forecast future annoyance in the course of a prospective airport expansion, opening of a new airport, or changes of the flight regime or operating plan. As such parameters change, they usually elicit a step change in exposure. There is evidence that a step change of noise exposure generally goes along with a so called "over-reaction" of the residents: With an increase of the exposure level, people are more annoyed than would be predicted by steady-state exposure-effect curves, whereas with a decrease of the level, they are less annoyed than would be predicted by the same curves (Fidell et al., 1985; Fidell et al., 2002; Griffiths and Raw, 1989). Although some models and tentative explanations have previously been published (Job, 1988b; Job and Hatfield, 2003), the mechanism of how residents judge their level of annoyance in response to the exposure change is not understood in detail. As pointed out by Fidell et al. (2002), the lack of information may partly be due to scarce opportunities to carry out field studies on the effect of abrupt and clear changes in noise exposure. It is useful, however, to seek a better understanding of these effects, in order to serve the interest of local governments, airport authorities, and the public in as precise as possible predictions of the effects of (future) changes of noise exposure.

In the current study, we addressed this issue by carrying out two annoyance surveys among residents around Zurich Airport, in Switzerland. The first survey was completed in August 2001, the second-employing almost identical methodology - was carried out two years later, during August 2003. Between these two surveys, in some communities to the east of the airport, the exposure situation changed considerably during shoulder hours (late evening and early morning) after new regulations, reducing air traffic over south German territory, were put into force in October 2001. As a consequence of these new regulations, residents to the east of the airport with no or only little experience in aircraft noise up to that point were newly overflown by inbound aircraft during shoulder hours. This quasiexperimental setting allowed for a detailed analysis of the effects of a step change in exposure to annoyance. To get an overview of the exposure around Zurich Airport and the local exposure change during the study period, Fig. 3 provides a map of the Zurich Airport region with exposure level contours for the year 2003, exposure change as grayscale gradient, and a schematic drawing of the runway layout.

\section{B. Background and study objectives}

Rapid and substantial changes in the nature of noise associated with commercial aviation have been a persistent feature of the industry since the 1950s. At Zurich, the total number of air traffic movements doubled between 1980 and 2000 , and reached its interim peak in the year 2000 with 325622 movements. In the aftermath of the demise of the airports most important customer, Swissair, which declared insolvency in October 2001, the number of aircraft movements decreased during the study period (2001: 309 230; 2002: 282 254; 2003: 269392 movements) but is taking up again nowadays. As has been discussed already, in such a changing context, we cannot assume that people react in the same way to aircraft noise as they did decades ago. The last aircraft noise annoyance surveys carried out in Switzerland date back to 1971 (Arbeitsgemeinschaft Für SozioPsychologische Fluglärmuntersuchungen, 1974) and 1991 (Oliva, 1998), respectively. In order to update our knowledge about resident's annoyance and their attitudes toward air traffic, a new series of surveys was carried out in 2001 and 2003.

The main research objectives were the following:

(1) provide an updated exposure-effect function for high annoyance among residents in the vicinity of Zurich Airport;

(2) investigate the impact of a step change (increase/ decrease) of aircraft noise exposure which, in some areas, took place between 2001 and 2003; provide a model that estimates the impact of change in exposure on high annoyance.

\section{METHODS}

\section{A. Questionnaire and telephone interviews}

The two surveys were carried out by mailed questionnaires (2001 and 2003) and in parts by computer assisted telephone interviews (2003) commissioned to a market research bureau. Both surveys 2001 and 2003 employed a noise annoyance questionnaire in written form that was mailed each survey year to 3360 addresses in the vicinity of the airport. Answers were collected between mid-August and September 10 (2001) and mid-October (2003), respectively. The respondents' addresses were selected according to a random procedure (described in Sec. II C). Respondents were asked to rate, among other aspects, their aircraft noise annoyance. For this purpose, the questionnaire included the German version of the 11-point annoyance scale from 0 to 10 recommended by ICBEN (Fields et al., 2001), as well as 7-point verbal scales with marks from "not annoyed at all" to "extremely annoyed," for rating different situations. The 11point annoyance questions referred to the civil aircraft noise experience of the respondents during the 12 preceding 
months. For both the 2001 and the 2003 surveys, the same questionnaire was used. A total of 510 telephone interviews were carried out in 2003, using the same order of questions and identical wording as in the written questionnaire form. Within the scope of a mixed model analysis described in Sec. III B, we found no evidence for an effect of survey method (questionnaire versus telephone interviews) on annoyance. We could therefore conclude that the cost-saving method of mail-distributed questionnaires is adequate for a study with the current aim and scope.

\section{B. Acoustical noise indicators}

For each respondent in both surveys, extensive noise exposure calculations based on the exact geographical location of the respondent's location of residence were made. The geographical coordinates for the modeling of the noise exposure were derived from the respondent's address using a geographical information system (GIS). The calculations were performed using the aircraft noise simulation model FLULA2 developed at Empa Materials Science and Technology (Krebs et al., 2004; Pietrzko and Hofmann, 1988; Thomann, 2007). The model delivers aircraft noise exposure data for an untilled terrain on a regular grid of $250 \mathrm{~m}$. For each respondent's place of residence, the exposure data were linearly interpolated. Noise exposure assessment with FLULA2 delivers the distribution of maximum sound pressure levels, the average sound pressure level $L_{A \text { eq }}$ for different time periods, as well as $L_{\mathrm{den}}$ and $L_{\mathrm{dn}}$. In order to be able to account for $1 \mathrm{~h}-L_{A \text { eq }}$ values and their influence on timeof-day-dependent noise sensitivity (preliminary results in Brink et al., 2007), for all respondents the 24 yearly average $1 \mathrm{~h}-L_{\text {Aeq }}$ values were calculated according to

$$
\begin{aligned}
L_{\text {Aeq, Hi }} & =10 \log \left(\frac{t_{0}}{t} \sum_{k} \sum_{j} N_{H j k} \times 10^{0.1 \cdot L_{A E i j k}}\right) \\
& =10 \log \left(\sum_{k} \sum_{j} N_{H j k} \times 10^{0.1 \cdot L_{A E i j k}}\right)+10 \log \left(\frac{t_{0}}{t}\right),
\end{aligned}
$$

where $L_{A E}$ is the calculated, averaged single exposure level in decibel at a specific immission point $i, L_{A \text { eq, Hi }}$ is the $A$-weighted average sound pressure level for the hour of the day $H$ at immission point $i, t$ is the averaging time in seconds, for any hour $3600 \mathrm{~s}, t_{0}$ is the reference time in seconds, $H$ is the hour of the day (example: $H=0$ is the hour from 00:00 to $00: 50: 59 ; H=19$ is hour 19:00 to $19: 59: 59$ ), $N$ is the number of movements during the averaging time, $j$ is the index for a specific aircraft type, $k$ is the index for a specific flight route, and $i$ is the index for a specific immission point.

In Eq. (1), $L_{A E i j k}$ is the averaged single event level from the aircraft type $j$ on the flight route $k$ at a specific immission point $i$. The simulation accounts for the real distance between source and receiver, the real flight paths, the geometric and the atmospheric attenuation, additional attenuation effects near the ground, and the spectral rotationally symmetric directivity of the source. The source models for 60 different aircraft types were derived from extensive acoustic measurements of aircraft movements on site (Krebs et al., 2004).
$N_{H j k}$ in Eq. (1) is the yearly average number of movements of the aircraft type $j$ on the flight route $k$ during the hour $H$. The $1 \mathrm{~h}-L_{\text {Aeq }}$ of the specific hour is then the energetic sum of all single event levels calculated at the specific immission point $i$. The hourly average sound pressure levels across $24 \mathrm{~h}$ are the basis for all the given noise exposure values used in the present article (see equations below). Error analysis investigations of the FLULA2 model by Thomann (2007) showed that it is possible to reach an extended uncertainty $(k=2 ; p=95 \%)$ of the calculated $1 \mathrm{~h}-L_{\text {Aeq }}$ between about 1.0 and $1.5 \mathrm{~dB}$. However, some systematic deviations from the widespread INM model (Olmstead et al., 2001) were found insofar as that the INM yields systematically lower levels in regions with $L_{\text {den }}$ below $55 \mathrm{~dB}$. This fact should be accounted for when comparing calculated levels from different models.

Noise exposure of respondents in this article is-for the most part—given in $L_{\mathrm{den}}$ values. The $L_{\mathrm{den}}$ is defined in terms of the average levels during day, evening, and night and has been proposed as the new uniform noise metric for the European Union (European Union, 2000). For comparison with other studies, the $L_{\mathrm{dn}}$ noise metric as well as the $L_{\mathrm{Aeq}, 24 \mathrm{~h}}$ metric will also be used. The metrics are calculated as follows:

$$
\begin{aligned}
L_{\text {Aeq, } 24 \mathrm{~h}} & =10 \log \left(\frac{1}{24} \cdot \sum_{H=0}^{23} 10^{0.1 \cdot L_{\text {Aeq }, H}}\right) \\
& =10 \log \left(\sum_{H=0}^{23} 10^{0.1 \cdot L_{\text {Aeq }, H}}\right)-10 \log (24) \\
L_{\mathrm{dn}}= & 10 \log \left(\frac{15}{24} \cdot 10^{0.1 \cdot\left(L_{\text {Aeq }, d^{+}}+K_{d}\right)}+\frac{9}{24} \cdot 10^{0.1 \cdot\left(L_{\text {Aeq }, n}+K_{n}\right)}\right) \\
= & 10 \log \left(\sum_{H=7}^{21} 10^{0.1 \cdot\left(L_{\text {Aeq }, H^{+}}+K_{d}\right)}+\sum_{H=22}^{6} 10^{0.11 \cdot\left(L_{\text {Aeq }, H^{+}}+K_{n}\right)}\right) \\
- & 10 \log (24)
\end{aligned}
$$

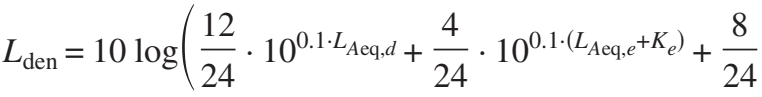

$$
\begin{aligned}
& \left.\times 10^{0.1 \cdot\left(L_{A \mathrm{eq}, n}+K_{n}\right)}\right) \\
& =10 \log \left(\sum_{H=7}^{18} 10^{0.1 \cdot L_{A \mathrm{eq}, H}}+\sum_{H=19}^{22} 10^{0.1 \cdot\left(L_{A \mathrm{eq}, H}+K_{e}\right)}\right. \\
& \left.+\sum_{H=23}^{6} 10^{0.1 \cdot\left(L_{\text {Aeq }, H^{+}}+K_{n}\right)}\right)-10 \log (24)
\end{aligned}
$$

where $K_{d}=0 \mathrm{~dB}, K_{e}=5 \mathrm{~dB}, K_{n}=10 \mathrm{~dB}$, and $L_{A \mathrm{eq}, d}, L_{A \mathrm{eq}, e}$, $L_{A \text { eq }, n}$ for the $L_{\text {den }}$ equation: $A$-weighted long term $L_{A \text { eq }}$ for the day $(0700-1900 \mathrm{~h})$, evening (1900-2300 h), and night $(2300-0700 \mathrm{~h})$ period at the immission point; for the $L_{\mathrm{dn}}$ equation: $A$-weighted long term $L_{A \text { eq }}$ for the day $(0700-2200 \mathrm{~h})$, and night $(2200-0700 \mathrm{~h})$ period at the immission point. 
TABLE I. $L_{\text {den }}$ exposure categories and number of the respondents for both rounds of the study (the category value denominates the midpoint of the $L_{\text {den }}$ category which contains all cases with levels from -2.5 to $+2.49 \mathrm{~dB}$ around the midpoint)

\begin{tabular}{lllll}
\hline \hline & $\begin{array}{l}\text { Survey 2001 } \\
\text { Number of } \\
L_{\text {den }} \\
\text { category }\end{array}$ & Percentage & $\begin{array}{l}\text { Survey 2003 } \\
\text { Number of } \\
\text { subjects }\end{array}$ & Percentage \\
\hline 30 & 0 & 0 & 142 & 8 \\
35 & 19 & 1 & 138 & 8 \\
40 & 314 & 17 & 84 & 5 \\
45 & 130 & 7 & 165 & 10 \\
50 & 503 & 28 & 511 & 30 \\
55 & 516 & 29 & 382 & 22 \\
60 & 241 & 13 & 209 & 12 \\
65 & 72 & 4 & 87 & 5 \\
70 & 21 & 1 & 1 & 0 \\
Total & 1816 & 100 & 1719 & 100 \\
\hline \hline
\end{tabular}

Exposure calculations for the survey 2003 were carried out on the basis of the flight operations (movements, fleet mix, and flight paths) during the year 2003. However, the calculation basis for the exposure assessment for the survey 2001 was the flight operations during 2000. The reason for this is that until September 11 in 2001, which was followed by a considerable decrease of air traffic worldwide, there were no relevant differences in exposure per resident between the year 2000 and the year 2001. Because flight routes have not changed either, noise exposure was comparable between the year 2000 and the year 2001 until about end of August. In addition to civil aircraft noise, a part of the respondents from both surveys experienced military jet noise from a military airfield of the Swiss Air Force located about $10 \mathrm{~km}$ southeast of the airport. In order to avoid a possible influence of the presence of - or occlusion through-military noise sources on the judgement of civil aircraft noise annoyance, the respondents (288 in the year 2001 and 269 in the year 2003) that experienced average military jet noise in excess of $50 \mathrm{~dB}\left(L_{A \text { eq,06:00-18:00 h }}\right)$ were excluded in the exposure-effect calculations that are presented in Sec. III B [as regards Fig. 1, and Eqs. (5) and (6)] and Sec. III C [as regards Table III model (C), Eq. (7), and Fig. 4].

\section{Sampling procedure}

As the (originally) more descriptive objective of the study was to obtain a representative picture of the extent of the aircraft noise annoyance problem in a larger population of people around the airport, the sampling strategy did not primarily aim at collecting data for as accurate as possible constructing exposure-effect relationships. Therefore, a quite large proportion of the sample only experienced rather moderate levels of aircraft noise (see Table I). Potential restrictions concerning interpretability of the study results are discussed in Sec. IV A.

\section{2001 survey}

The local authorities of all 68 municipalities that were geographically located within a radius of $20 \mathrm{~km}$ around the airport were requested to provide census and address infor- mation of their inhabitants. From the initial 68 municipalities enquired, a total of 56 agreed to relinquish their address data to us, provided the data were used solely for the intended research purpose and destroyed afterwards. For the 2001 survey, in each municipality, a random sample of 60 inhabitants was drawn which have been living at their current homes for at least one year and who were in the age range from 18 years and up, giving a sample size of 3360 . It has to be emphasized that, unlike is the case with address-based sampling techniques, we obtained a random sample of individuals, which means the sample is a true random sample of the municipality population and not just a random sample of available addresses. In the year 2001, from the 3360 forwarded questionnaires, 1816 were returned which amounts to a response rate of 54\%. The lowest response rate of a municipality was $32 \%$, and the highest was $90 \%$. Aircraft noise $L_{\text {den }}$ levels ranged from 35 to $70 \mathrm{~dB}(\mathrm{~A})$ in the sample. No significant correlation was found between the response rate of a municipality and the average $L_{\mathrm{den}}$ of its respondents.

\section{2003 survey}

For the 2003 survey, 747 respondents from the 2001 survey were again asked to participate in the 2003 survey because they had agreed that their addresses were kept with us for possible future surveys. This pool of 747 addresses was replenished up to a total of 3360 addresses. As in 2001, nonresponders were reminded after about a month after mailing the questionnaire. 1209 questionnaires were sent back in total (giving a response rate of 36\%). The lowest response rate of a municipality was $20 \%$ and the highest was $53 \%$. In 2003 we additionally conducted 510 telephone interviews-30 per municipality-in 17 selected municipalities in different areas around the airport, using the same questionnaire. In total, 1719 records were collected for the survey 2003 (510 telephone interviews, 394 reinterviewed, and 815 new respondents). Aircraft noise $L_{\text {den }}$ levels ranged from 29 to $68 \mathrm{~dB}(\mathrm{~A})$ in the sample. No significant correlation was found between the response rate for a municipality and the average $L_{\mathrm{den}}$ of its respondents.

\section{RESULTS}

\section{A. Descriptives}

In the year 2001 survey, $49.6 \%$ of the respondents were female, and $50.4 \%$ were male. The age of the respondents covered a range between 18 and 98, and the average was 47.37 years. The age class distribution was as follows: younger than 20 years: 4\%, 20-40: 33\%, 40-60: 41\%, and older than 60 years: $22 \%$. In the year 2003 survey, $42.2 \%$ of the respondents were female and $57.8 \%$ were male. The age of the respondents covered a range between 18 and 95, and the average was 50.89 years. The age class distribution was as follows: younger than 20 years: 1\%, 20-40: 28\%, 40-60: $41 \%$, and older than 60 years: $30 \%$.

Table I displays an overview over the number of respondents in each $L_{\mathrm{den}}$ exposure category for two rounds of study.

As can be derived from Table I, a quite large proportion of respondents were affected by only moderate aircraft noise 

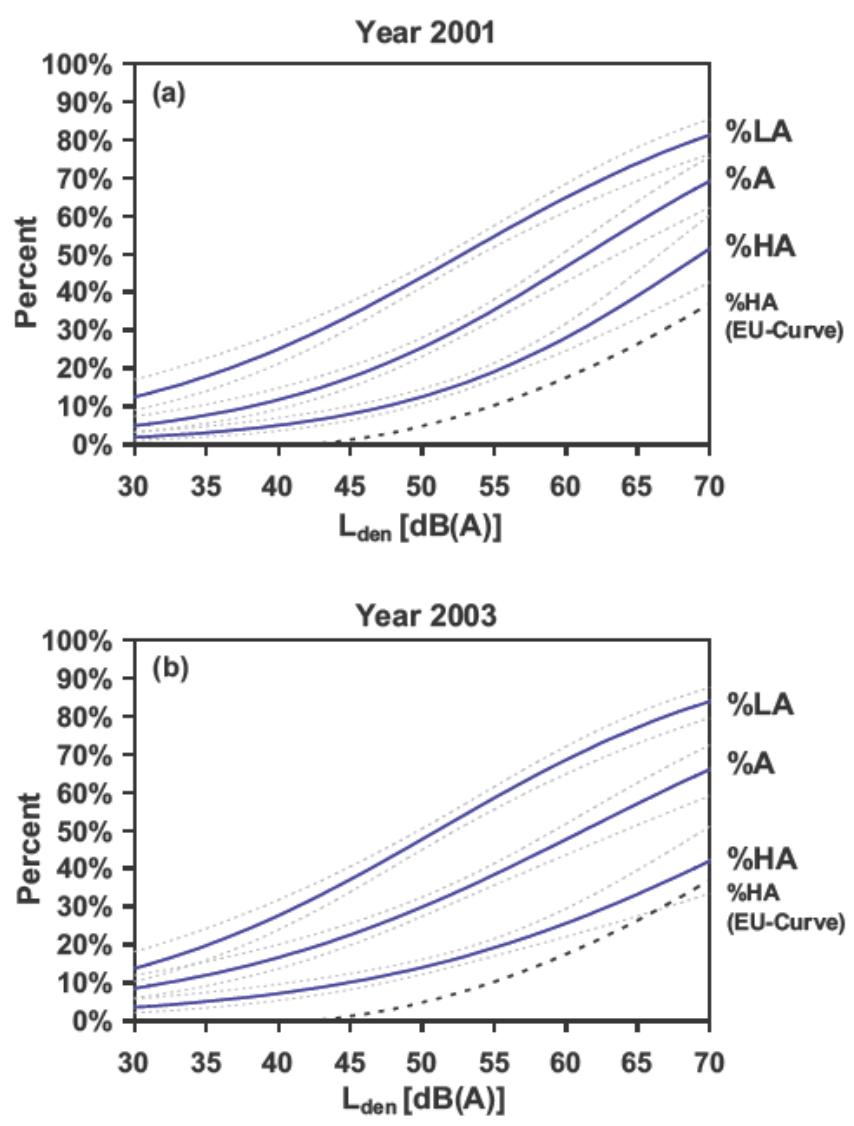

FIG. 1. (Color online) Percent little annoyed (\%LA), annoyed (\%A), and highly annoyed (\%HA) as a function of $L_{\mathrm{den}}$, with $95 \%$ confidence limits. (a) Survey 2001, $N=1538$. (b) Survey 2003, $N=1452$. The EU-curve (European Commission, 2002) for \%HA is shown for comparison.

exposure as expressed in the $L_{\mathrm{den}}$. This is because the respective sample is a random sample drawn from an area with almost 400000 inhabitants.

\section{B. Exposure-effect relationships in the years 2001 and 2003}

To determine the relationship between noise exposure metrics and the degree of annoyance, we modeled the exposure-effect relationship for the percentage of "little annoyed" (\%LA), "annoyed" (\%A), and "highly annoyed" $(\% \mathrm{HA})$ persons using logistic regression analysis. \%HA is the most widely used indicator whereas the $\% \mathrm{LA}$ and $\% \mathrm{~A}$ indicators better reflect annoyance at rather low exposure levels. The value of the variable HA was defined as 1 if the answer on the annoyance scale ( $0-10$ points) of the questionnaire was greater or equal 8 points. Variable A was coded as 1 when it was greater or equal 6 points, and variable LA when it was greater or equal 4 points. The regression calculations were made with SAS PROC LOGISTIC (SAS version 9, SAS Institute, Cary, NC). Figure 1 shows the curve estimators from the logistic regressions with the $L_{\mathrm{den}}$ noise metric, together with their $95 \%$ confidence intervals and-for the purpose of comparison-the EU curve (European Commission, 2002).

The percentages of persons expressing different grades of annoyance can be estimated using the logistic functions given in Eqs. (5) $\left(L_{\mathrm{den}}\right)$ and (6) $\left(L_{\mathrm{dn}}\right)$.

$$
\begin{aligned}
& \% \mathrm{HA}_{2001}=100 \cdot\left[1+\exp \left(-\left[0.10 \cdot L_{\mathrm{den}}-6.93\right]\right)^{-1}\right] \\
& \% \mathrm{HA}_{2003}=100 \cdot\left[1+\exp \left(-\left[0.07 \cdot L_{\mathrm{den}}-5.52\right]\right)^{-1}\right], \\
& \% \mathrm{~A}_{2001}=100 \cdot\left[1+\exp \left(-\left[0.09 \cdot L_{\mathrm{den}}-5.78\right]\right)^{-1}\right] \\
& \% \mathrm{~A}_{2003}=100 \cdot\left[1+\exp \left(-\left[0.08 \cdot L_{\mathrm{den}}-4.64\right]\right)^{-1}\right] \\
& \% \mathrm{LA}_{2001}=100 \cdot\left[1+\exp \left(-\left[0.08 \cdot L_{\mathrm{den}}-4.50\right]\right)^{-1}\right] \\
& \% \mathrm{LA}_{2003}=100 \cdot\left[1+\exp \left(-\left[0.09 \cdot L_{\mathrm{den}}-4.44\right]\right)^{-1}\right] \\
& \% \mathrm{HA}_{2001}=100 \cdot\left[1+\exp \left(-\left[0.10 \cdot L_{\mathrm{dn}}-6.93\right]\right)^{-1}\right] \\
& \% \mathrm{HA}_{2003}=100 \cdot\left[1+\exp \left(-\left[0.07 \cdot L_{\mathrm{dn}}-5.29\right]\right)^{-1}\right] \\
& \% \mathrm{~A}_{2001}=100 \cdot\left[1+\exp \left(-\left[0.10 \cdot L_{\mathrm{dn}}-6.03\right]\right)^{-1}\right] \\
& \% \mathrm{~A}_{2003}=100 \cdot\left[1+\exp \left(-\left[0.07 \cdot L_{\mathrm{dn}}-4.54\right]\right)^{-1}\right], \\
& \% \mathrm{LA}_{2001}=100 \cdot\left[1+\exp \left(-\left[0.09 \cdot L_{\mathrm{dn}}-4.80\right]\right)^{-1}\right] \\
& \% \mathrm{LA}_{2003}=100 \cdot\left[1+\exp \left(-\left[0.08 \cdot L_{\mathrm{dn}}-4.35\right]\right)^{-1}\right]
\end{aligned}
$$

In general, as it becomes evident from both the curves in Fig. 1 and Eqs. (5) and (6), community annoyance is an increasing function of the $L_{\mathrm{den}} / L_{\mathrm{dn}}$. The function curves run about parallel with the generalized curves from Miedema and Oudshoorn (2001), including the EU curve for the $L_{\mathrm{den}}$ but are shifted toward the left by about $5-10 \mathrm{~dB}$. This shows that the percentage highly annoyed at a given exposure level in Zurich is actually higher than would be predicted by the Miedema and Oudshoorn curves.

Fidell et al. (1985) hypothesized that public awareness of a (upcoming) step change may be enough to evoke higherthan-predicted annoyance. After the necessity of installing new flight routes over in part densely populated areas has been announced by the airport authorities in the year before the first survey 2001 took place, the aircraft noise issue in Zurich received considerable attention by the media. After the new routes were (partly) established in fall 2001, the public interest increased even more and aircraft noise became a top issue on the local political agenda after 2001 (and it is still today). Moderating factors other than mere exposure, such as heightened noise awareness through, e.g., vast media coverage, might evoke a shift of the exposure-effect relationship. Therefore, with a data set where the samples from 2001 and 2003 were merged into one data set, an additional logistic regression analysis was carried out to determine whether the year of the survey has had an impact on annoyance, independent of particular changes in the immission situation. Because in 2003, almost 400 respondents were already represented in the 2001 sample, we treated the year as fixed and the respondent as random effect and used SAS's GLIMMIX procedure to model high annoyance as depending on the year of survey, the survey method (mailed questionnaire versus telephone interview), and the $L_{\mathrm{den}}$. The tests of fixed effects did not provide any evidence for an effect of survey method (questionnaire versus telephone in- 
terviews) $[F(1)=0.25 ; p=.62]$, nor could we find evidence for a year-of-survey effect $[F(1)=.67 ; p=.41]$.

\section{Effects of a step change in exposure between 2001 and 2003}

Abrupt changes in noise exposure usually produce a change in reaction that is much greater than would be predicted from the change in sound exposure with exposureeffect functions that assume stable conditions (Guski, 2001; Van Kempen and Van Kamp, 2005). In general, when noise exposure increases, the level of annoyance increases to a level that is well beyond than would be expected if the new noise level had existed for a long time. The parallel effect exists for reductions in noise exposure, such that the reaction to the reduced noise is less than would be expected if the new low level had existed for many years. These effects are generally termed "over-reaction effects" to reflect the exaggerated reaction to changes in noise exposure in either direction. Raw and Griffiths (1990) claimed that over-reaction effects can be seen up to nine years after the change.

In the current study we aimed at determining the size range of such an over-reaction effect by taking advantage of the change in the operating plan of the airport that took place between the years the two surveys were carried out. It appears necessary to operationalize change in terms of either an increase or a decrease of number of operations or as a change of average sound exposure which is beyond the amount of normal fluctuations usually observable at airports (Horonjeff and Robert, 1997). The aircraft noise exposure situation around Zurich Airport at the beginning of this decade was characterized by a stepwise adaptation of the operating plan during shoulder hours between October 2001 and October 2003 which, for particular communities, resulted in a substantial change of the shoulder hour exposure. Until October 2001 , about $95 \%$ of all inbound air traffic to Zurich used German airspace for the final approach on either Runway 14 or 16 (see Fig. 3), the German border being just about $15 \mathrm{~km}$ north of the runway ends. As a consequence of newly impeded restrictions pertaining to the usage of south German airspace which were put into force by the German government as of October 19, 2001 (two months after the first survey), the operating plan of the airport was adjusted in basically three subsequent steps that happened during the following one and a half years. By May 2003 almost all inbound flights during $6: 00-7: 00 \mathrm{~h}$ and $21: 00-24: 00 \mathrm{~h}$ on weekdays and between $6: 00-9: 00 \mathrm{~h}$ and $20: 00-24: 00 \mathrm{~h}$ on weekends were relocated from the former northern approach route to landing on Runway 28, now overflying eastern communities not previously affected by aircraft landings. The largest step change in the number of movements occurred after April 2003 when a new instrument landing system (ILS) for Runway 28 begins its operation. The number of shoulder hour landing approaches (06-09 $\mathrm{h}$ and 21-23 h) onto that runway during the traffic intense months of June, July, and August raised from 377 in 2001, to 919 in 2002, and to 4748 in 2003. Figure 2 shows the development of aircraft movements on the approach path onto Runway 28 (overflying eastern communities of Kloten, Bassersdorf, Nü-

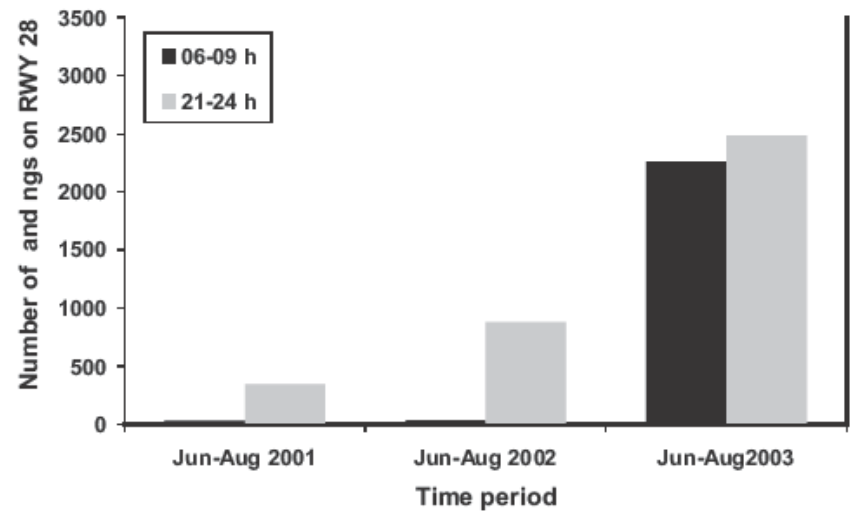

FIG. 2. Number of aircraft landings onto Runway 28 during the months of June, July, and August, in the years 2001, 2002, and 2003.

rensdorf, Lindau, Illnau-Effretikon, Weisslingen, and Zell) during shoulder hours in the years 2001, 2002, and 2003.

Considering the fact that the total number of operations at Zurich Airport actually decreased after September 2001, the more than tenfold local increase in the numbers of landing flights in the morning affecting the east can, for this particular region, be considered a substantial step change. Of course, the changes introduced between 2001 and 2003 as well as the general decline of air traffic in the same time period resulted in a decrease of exposure in many other communities, particularly north of the airport. Figure 3 displays the difference of the daily average $L_{A \mathrm{Aq}, 06-22 \mathrm{~h}}$ between the year 2000 and the year 2003 as a grayscale gradient drawn on a map of the area around the airport.

The magnitude of a (step) change can be conceptualized as exposure difference (in the sense of "current exposure" minus "previous exposure" or "new exposure" minus "old exposure") and be used as a covariate in a exposure-effect relationship model. As concerns the measure to express this change, differences of average levels best seem to serve the purpose of forecasting annoyance after changes at airports because in most instances (hourly) average levels are readily available, at least more so than, e.g., a number of aircraft movements above a certain threshold or other means of expressing exposure. As mentioned, major changes in exposure to aircraft noise between 2001 and 2003 occurred predominantly during shoulder hours; therefore, to create a variable of change for each respondent in the subsample between 2001 and 2003, we calculated the difference of the $L_{\text {Aeq }}$ for the time period from 6:00 to $9: 00 \mathrm{~h}$ and the time period from 21:00 to $24: 00 \mathrm{~h}$.

In the current study, related records for both surveys, which allow to derive the change effect, were available for the group of respondents that were interviewed twice $(N$ =394). The largest differences in exposure between the years 2001 and 2003 in this subsample appeared in the early morning between 6:00 and 7:00 $\mathrm{h}$ with the highest $1 \mathrm{~h}-L_{\text {Aeq }}$ level difference of a respondent at $+20.3 \mathrm{~dB}$. Table II shows the frequency distribution of the amounts of change in the subsample between 2001 and 2003. As is evident from Table II, the exposure in 2003 decreased for a majority of respondents, mostly because of the demise of the Swissair company 


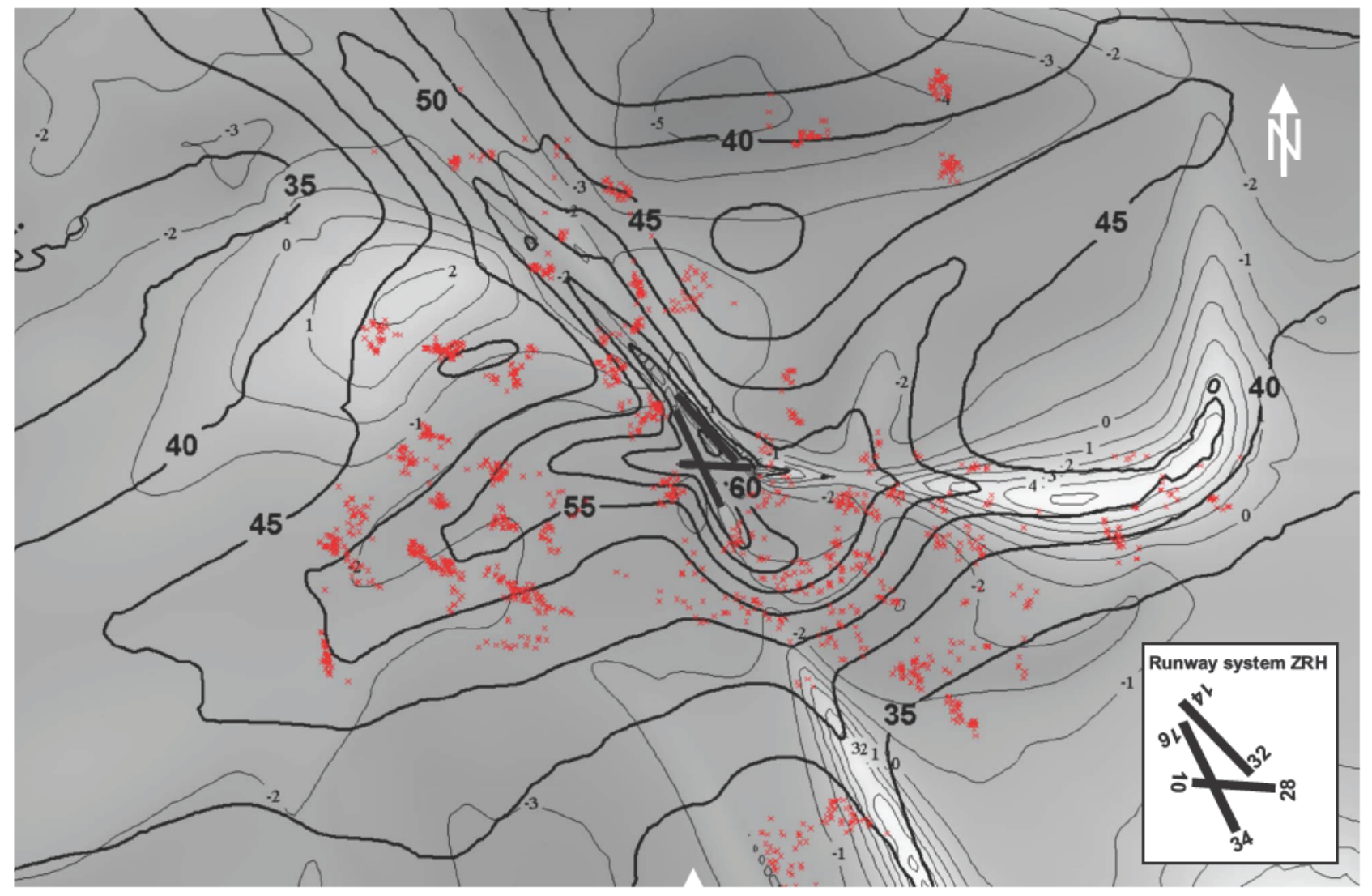

FIG. 3. (Color online) Aircraft noise exposure differences around Zurich Airport in $1 \mathrm{~dB}$ steps between the average daily exposure in the year 2003 and the average daily exposure in the year 2000. Negative differences stand for a higher level in 2000 , and positive differences for a higher level in 2003 . The grayscale gradient reaches from the lowest (dark gray=exposure decrease) to the highest differences (white=exposure increase). The bold curves show the exposure contours of the $L_{\text {Aeq, } 06-22 \mathrm{~h}}$ for the year 2003. The crosses correspond to the places of living of the respondents from the 2001 survey.

in fall 2001 and probably also due to the general reduction of air traffic in the aftermath of the terrorist attacks of September 11.

Two logistic regression models were specified in order to test the influence of the noise exposure level in 2003, as defined by the $L_{\mathrm{den}}$, and the differences of the noise exposure level between 2001 and 2003 during morning and late evening, as well as the interaction between the two variables, on the presence of high annoyance in 2003. The first model (a) contained the change of the $L_{\text {Aeq }}$ in the morning $(6: 00-9: 00 \mathrm{~h})$, and the second model (b) contained the change during late evening $(21: 00-24: 00 \mathrm{~h})$. As the interactions between the $L_{\mathrm{den}}$ and the differences were not significant in both models, the interaction term was eliminated from both models.

In addition to these two models, we calculated an "average" model (c) for the probability of high annoyance using all responses from both years from people whose place of residence did not exceed $50 \mathrm{~dB}(\mathrm{~A}) L_{\text {Aeq, } 6-18 \mathrm{~h}}$ of military jet noise exposure. For the subset of people meeting this criterion and who were interviewed twice $(N=331)$, the exposure

TABLE II. Frequency distribution of the exposure difference during shoulder hours in the subsample of twice-interviewed respondents.

\begin{tabular}{llllllll}
\hline \hline & \multicolumn{3}{c}{ Morning $(6: 00-9: 00 \mathrm{~h})$} & & \multicolumn{3}{c}{ Evening $(21:-24: 00 \mathrm{~h})$} \\
\cline { 2 - 4 } $\begin{array}{c}\text { Exposure difference } \\
(2003-2001)\end{array}$ & Count & Percent & $\begin{array}{l}\text { Cumulative } \\
\text { percent }\end{array}$ & & Count & Percent & $\begin{array}{l}\text { Cumulative } \\
\text { percent }\end{array}$ \\
\hline$\geq 12 \mathrm{~dB}$ & 0 & 0 & 0 & 0 & 0 & 0 \\
$\geq 9 \mathrm{~dB}$ & 9 & 2 & 2 & 4 & 1 & 1 \\
$\geq 6 \mathrm{~dB}$ & 15 & 4 & 6 & 31 & 8 & 9 \\
$\geq 3 \mathrm{~dB}$ & 18 & 13 & 24 & & 52 & 13 & 24 \\
$\geq 0 \mathrm{~dB}$ & 51 & 13 & 24 & 52 & 13 & 24 \\
$\geq-3 \mathrm{~dB}$ & 161 & 41 & 64 & 178 & 45 & 70 \\
$\geq-6 \mathrm{~dB}$ & 83 & 21 & 86 & 77 & 20 & 89 \\
$\geq-9 \mathrm{~dB}$ & 34 & 9 & 94 & 39 & 10 & 99 \\
$\geq-12 \mathrm{~dB}$ & 23 & 6 & 100 & 4 & 1 & 100 \\
\hline \hline
\end{tabular}


TABLE III. Parameter estimates for three logistic regression models modelling the probability of high annoyance

\begin{tabular}{|c|c|c|c|c|c|c|c|}
\hline Model & & Parameter & Estimate & SE & $p$ & 95\% Lower CI & 95\% Upper CI \\
\hline \multirow{3}{*}{\multicolumn{2}{|c|}{ (a) Morning $(N=394)$}} & Intercept & -4.53 & 1.31 & 0.00055 & -7.10 & -1.96 \\
\hline & & $L_{\mathrm{den}}$ & 0.05 & 0.03 & 0.00003 & 0.01 & 0.1 \\
\hline & & $\begin{array}{l}\text { Change of } \\
L_{\text {Aeq, } 06: 00-09: 00 \mathrm{~h}}\end{array}$ & 0.16 & 0.04 & 0.02830 & 0.08 & 0.23 \\
\hline \multirow{3}{*}{\multicolumn{2}{|c|}{ (b) Evening $(N=394)$}} & Intercept & -5.32 & 1.31 & 0.00005 & -7.9 & -2.75 \\
\hline & & $L_{\mathrm{den}}$ & 0.07 & 0.03 & 0.00554 & 0.02 & 0.12 \\
\hline & & $\begin{array}{l}\text { Change of } \\
L_{\text {Aeq, } 21: 00-24: 00 \mathrm{~h}}\end{array}$ & 0.16 & 0.04 & 0.00002 & 0.09 & 0.24 \\
\hline \multirow[t]{6}{*}{ (c) Average $(N=2685)$} & $\left(L_{\mathrm{den}}\right)$ & Intercept & -6.10 & 0.44 & $<0.00001$ & -6.96 & -5.25 \\
\hline & & $L_{\mathrm{den}}$ & 0.09 & 0.008 & $<0.00001$ & 0.07 & 0.1 \\
\hline & $\left(L_{\mathrm{dn}}\right)$ & Intercept & -6.12 & 0.45 & $<0.00001$ & -7 & -5.24 \\
\hline & & $L_{\mathrm{dn}}$ & 0.08 & 0.008 & $<0.00001$ & 0.06 & 0.1 \\
\hline & $\left(L_{\text {Aeq, } 24 \mathrm{~h}}\right)$ & Intercept & -5.33 & 0.39 & $<0.00001$ & -6.09 & -4.57 \\
\hline & & $L_{\text {Aeq }, 24 \mathrm{~h}}$ & 0.08 & 0.008 & $<0.00001$ & 0.06 & 0.09 \\
\hline
\end{tabular}

was calculated as the energetic, and the annoyance (on the 11-point scale) as the arithmetic mean of both years. The response code 1 (indicating high annoyance) was assigned to scale values greater or equal 8 . The data set for the average model (c) consisted of 2685 individual cases (1230 from the year 2001, 1124 from the year 2003, and 331 from both years). Three logistic regression models were calculated with $L_{\mathrm{den}}, L_{\mathrm{dn}}$, and $L_{\mathrm{Aeq}, 24 \mathrm{~h}}$ as predictors. Table III displays the parameter estimates for these models.

Presently, the three average models in Table III (c) covering the $L_{\mathrm{den}}, L_{\mathrm{dn}}$, and $L_{\mathrm{Aeq}, 24 \mathrm{~h}}$ noise metric represent the best available estimation of the exposure-effect relationship between aircraft noise and high annoyance for the population around Zurich Airport. The following polynomial approximations of the three models are easier to use and sufficiently accurate in the range between 30 and $70 \mathrm{~dB}$ $L_{\mathrm{den}} / L_{\mathrm{dn}} / L_{\text {Aeq, } 24 \mathrm{~h}}:$

$$
\begin{aligned}
\% \mathrm{HA}\left(L_{\mathrm{den}}\right)= & \left(0.0758-0.0027 \cdot L_{\mathrm{den}}-2.196\right. \\
\times & \left.10^{-5} \cdot L_{\mathrm{den}}^{2}+1.9982 \times 10^{-6} \cdot L_{\mathrm{den}}^{3}\right) \cdot 100, \\
\% \mathrm{HA}\left(L_{\mathrm{dn}}\right)= & \left(0.0498-0.0009 \cdot L_{\mathrm{dn}}-5.9509\right. \\
\times & \left.10^{-5} \cdot L_{\mathrm{dn}}^{2}+2.1983 \times 10^{-6} \cdot L_{\mathrm{dn}}^{3}\right) \cdot 100, \\
\% \mathrm{HA}\left(L_{\text {Aeq, } 24 \mathrm{~h}}\right)= & \left(0.3011-0.0193 \cdot L_{\text {Aeq }, 24 \mathrm{~h}}\right. \\
& +0.0004 \cdot L_{\text {Aeq }, 24 \mathrm{~h}}^{2}-9.5435 \\
& \left.\times 10^{-7} \cdot L_{\text {Aeq, } 24 \mathrm{~h}}^{3}\right) \cdot 100 .
\end{aligned}
$$

Figure 4 shows the exposure-effect curves as predicted with the models (a) and (b) from Table III. The curves for a $5 \mathrm{~dB}$ change are drawn as an arbitrary example. They can be regarded as an estimate of the "current" (2003) exposure-effect relationship for the part of the population which experienced a $5 \mathrm{~dB}$ change during shoulder hours since 2001. The "no change" curve reflects the estimation of the exposure-effect relationship for the steady state condition in the sample. For an $L_{\mathrm{den}}$ exposure in the $50-70 \mathrm{~dB}$ range, a recent $5 \mathrm{~dB}$ step increase during shoulder hours results in about 15\%-20\% more highly annoyed persons than would be predicted for the same $L_{\mathrm{den}}$ but under steady state conditions.

The curves in both graphs in Fig. 4 show the shift of the exposure-effect-curve when a recent change of exposure in either the morning or evening hours comes into play. The shift of the curve on the $X$-axis per decibel of change is
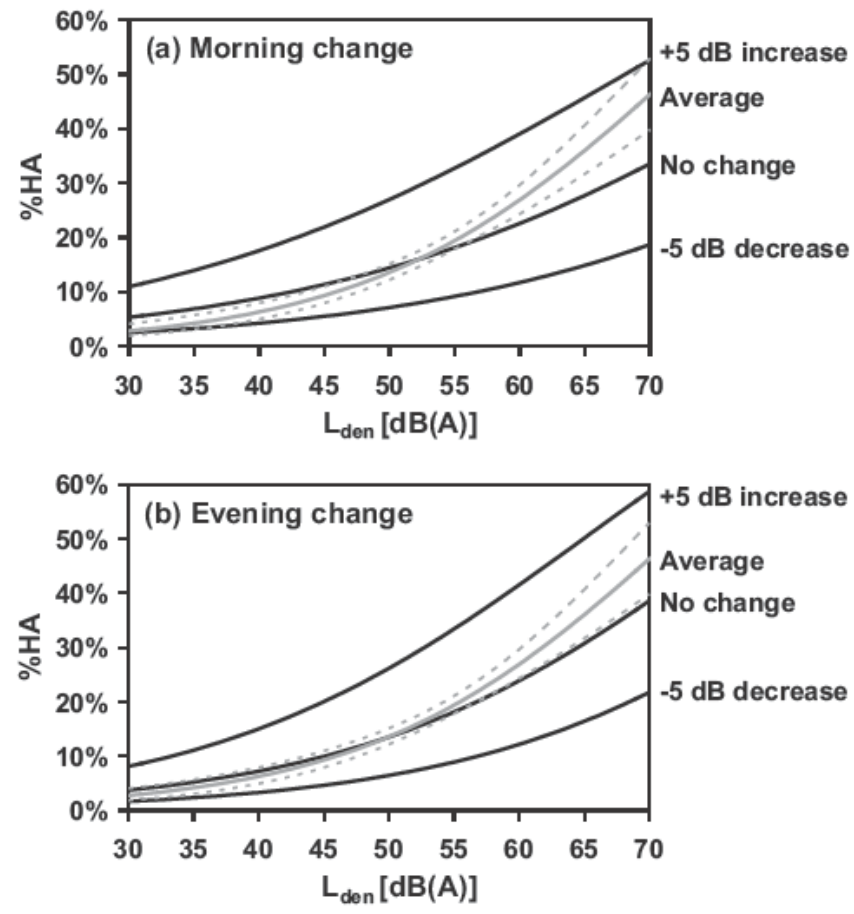

FIG. 4. Estimated curves of the percentage of highly annoyed respondents $(\% \mathrm{HA})$ in the year 2003 which were also interviewed in 2001 as a function of $L_{\mathrm{den}}$ in 2003. Curves are shown for unchanged exposure ( $\left.0 \mathrm{~dB}\right)$, a $5 \mathrm{~dB}$ step increase, and a $5 \mathrm{~dB}$ step decrease of exposure according to the parameters from Table III. In addition, the curve for the average model including 95\% confidence boundaries is shown. (a) Morning change (change of $L_{\text {Aeq, } 06-09 \mathrm{~h}}$ ). (b) Evening change (change of $L_{\text {Aeq, } 06-09 \mathrm{~h}}$ ) 

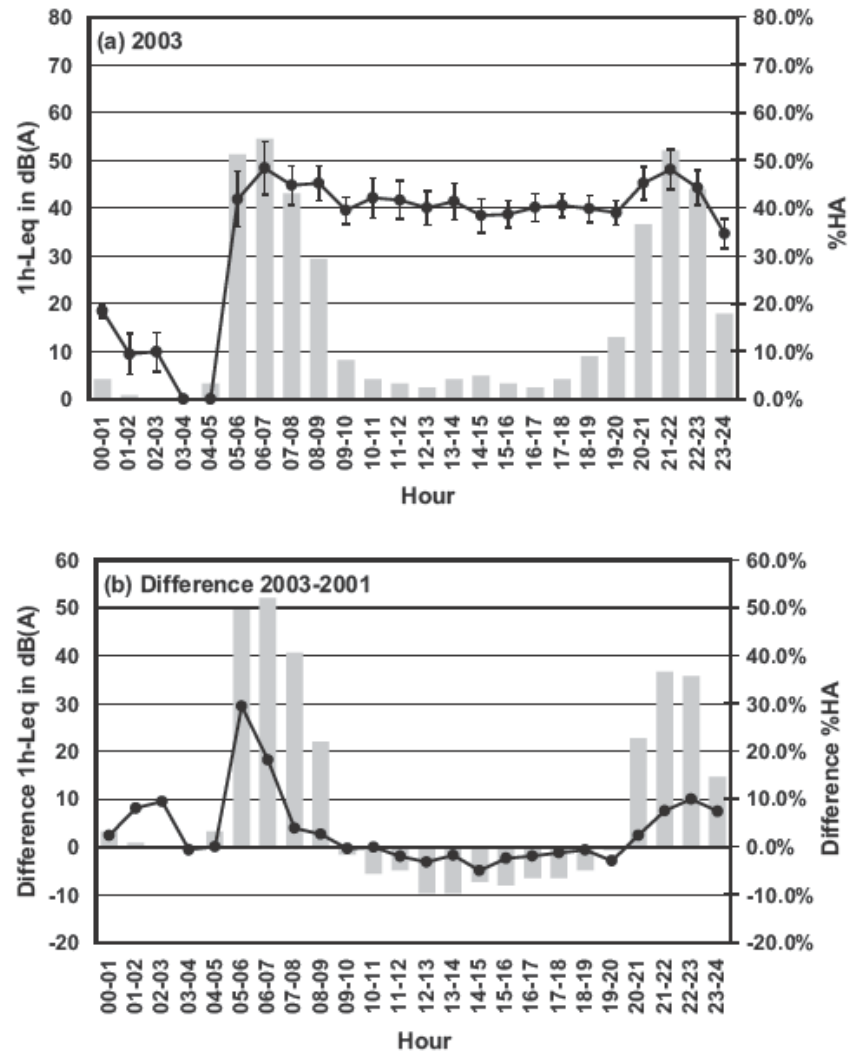

FIG. 5. (a) Percentage of highly annoyed respondents per hour of day (right axis; columns) in four municipalities east of the airport along with the arithmetic average $1 \mathrm{~h}-L_{A \propto q}$ value (left axis; line with round markers including standard deviation error bars) in the year 2003. (b) Difference of the percentage of highly annoyed respondents in the same group of municipalities, per hour of day, and corresponding difference of the $1 \mathrm{~h}-L_{A \propto q}$ between the years 2003 and 2001.

equivalent to the ratio of the estimates for the change effect and the $L_{\text {den }}$ effect as given in Table III, i.e., for the morning model, $2.87 \mathrm{~dB}$, and for the evening model, $2.35 \mathrm{~dB}$. Depending on the time of day for which one wants to model the impact of change, one might use either model (a) (if the change pertains to morning hours) or (b) (if the change pertains to evening hours) to predict annoyance after a change in exposure.

\section{Changing diurnal variation of annoyance as result of a step change in exposure during shoulder hours}

Due to the fact that activities vary across the day, it is plausible to assume that people's responses to noise immissions differ depending on the time/hour of day a particular amount of exposure affects them. Retrospective data on particularly annoying times of day can be collected by asking respondents to mark particular hours of high annoyance in an array of hours of day presented in a questionnaire or in similar form. We investigated diurnal annoyance by asking the respondents for particular times during the day, when they felt highly annoyed in an open question. Up to three time periods could be indicated. The English translation of that particular item in the questionnaire read as follows:
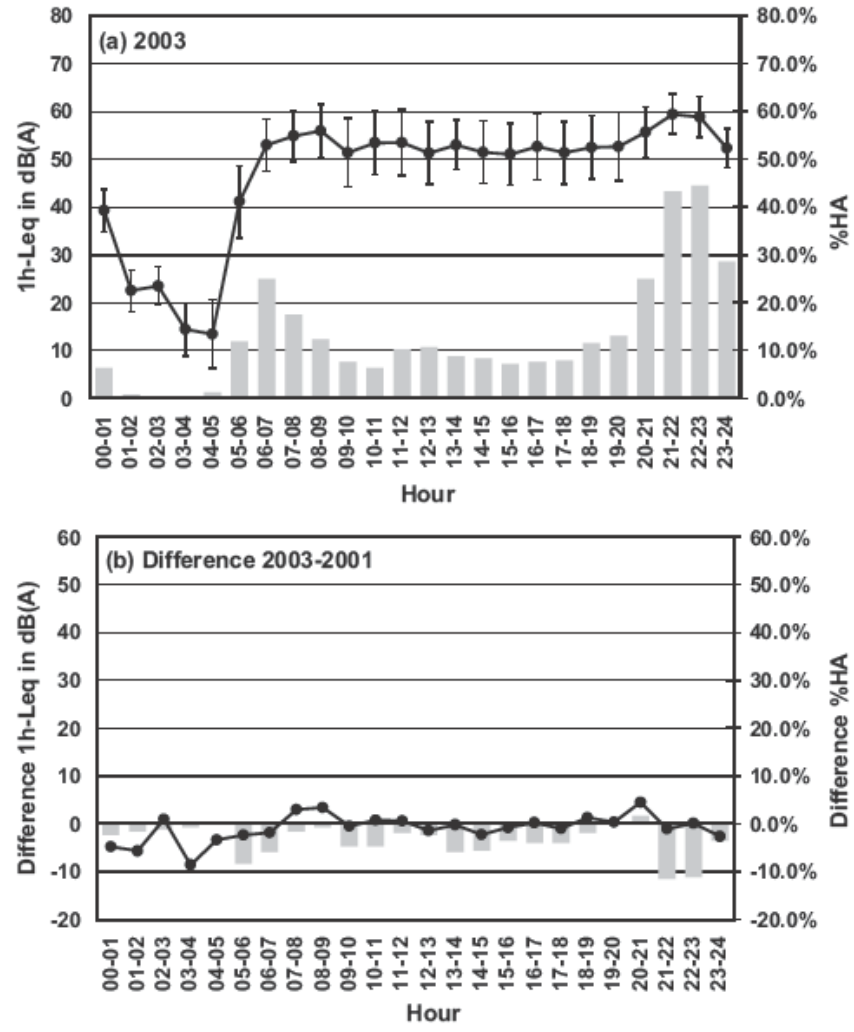

FIG. 6. (a) Percentage of highly annoyed respondents per hour of day (right axis; columns) in seven municipalities north of the airport along with the arithmetic average $1 \mathrm{~h}-L_{\text {Aeq }}$ value (left axis; line with round markers including standard deviation error bars) in the year 2003. (b) Difference of the percentage of highly annoyed respondents in the same group of municipalities, per hour of day, and corresponding difference of the $1 \mathrm{~h}-L_{\text {Acq }}$ between the years 2003 and 2001 .

"Are you being particularly highly annoyed (whatever day in the week) by aircraft noise at certain times?' If yes, please indicate these time periods in a 00-24 h format. ( ) no ( ) yes, from:.....to:.....h from:.....to:.....h from:......to:......h

The data from that item were used to determine from each respondent, for each hour, the occurrence of "high annoyance" which was coded as either " 0 " (no particular annoyance) or " 1 " (highly annoyed at that particular hour). We chose this form of questioning mainly for reasons of space (on the questionnaire). It does not adhere to the ICBEN recommendations of gathering annoyance data for deriving exposure-effect relationships, so any binary high annoyance statement of the respondents each hour may not reflect the same degree of annoyance, which would be found with the recommended wording and scales from Fields et al., (2001). However, it is reasonable to assume that both forms of questioning correlate. Respondents not indicating any particular time of high annoyance, which means answering the above question with "no," were still considered valid cases that were not highly annoyed at any time of day.

In Figs. 5(a) and 6(a) the diurnal annoyance profiles, expressed as percentage of respondents claiming to be highly annoyed as determined with the above question, along with the corresponding $1 \mathrm{~h}-L_{\mathrm{Aeq}}$ values of the decisively new af- 
fected communities with increasing exposure during late evening and early morning (municipalities of IllnauEffretikon, Lindau, Weisslingen, and Zell; $N=154$ ) are compared with seven communities to the north (municipalities of Bülach, Glattfelden, Hochfelden, Höri, Niederglatt, Oberglatt, and Stadel; $N=238$ ) which benefited from the new operating plan in terms of slightly decreasing exposure.

Respondents from the communities to the east (Fig. 5) which received "new" noise from landing aircraft during shoulder hours express a rather clear over-reaction in the year 2003. Their degree of annoyance during shoulder hours, as compared to the communities to the north (Fig. 6), which are affected by even higher exposure values (mostly from takeoffs), is higher. During early morning between 5:00 and 7:00 h, almost all annoyance reported in this group is new because the percentage difference as compared to 2001 [Fig. $5(b)]$ is about the same as the actual annoyance in 2003. The relocation of incoming flights to the eastern region is reflected in decreasing annoyance in the northern communities [Fig. 6(b)] in the hours of 5:00-7:00 and 21:00-23:00.

The data demonstrate in a descriptive fashion that a quite strong over-reaction effect exists in the eastern communities which seems to be specific to particular times during the day.

\section{CONCLUDING REMARKS}

\section{A. Study design and uncertainty}

The sampling strategy of the current study did not primarily aim at collecting data for as accurate as possible constructing exposure-effect relationships but rather to obtain a representative picture of aircraft noise annoyance incidences in a larger population around the airport. Therefore, no systematic exposure level stratification was aimed for and consequentially, a quite large proportion of the sample only experienced rather moderate levels of aircraft noise (see Table I). This could be considered a weakness of the design. Since low levels are generally more afflicted with uncertainty of the acoustic calculations, impact assessment at lower acoustic levels is more uncertain too. However, we have evidence that also low levels of noise can still elicit annoyance reactions and, given the relatively large numbers of people experiencing these kinds of low and moderate levels around many airports, surely deserve study. The combined sample size of 3535 respondents over the two survey years was comparatively large.

The confidence intervals of the exposure-effect functions in Figs. 1 and 4 and the standard errors reported in Table III pertain to the uncertainty of the annoyance measurement in the sample (the $Y$-axis) not the uncertainty of exposure calculations (the $X$-axis). Therefore, the "physically true" confidence boundaries are most probably wider. We did not calculate the extended uncertainty of the exposure-effect relationship since the nonconsideration of acoustic uncertainty is a shortcoming of almost all annoyance studies of this kind. Accounting for acoustic uncertainty would possibly compromise the comparability of the confidence intervals in this study with the ones from other studies.

\section{B. Exposure-effect relationships}

The two surveys carried out around Zurich Airport in 2001 and 2003 provide the most up to date exposure-effect functions for aircraft noise in Switzerland. The $L_{\text {den }}$ function curve for the average model [Eq. (7)] runs about parallel with the generalized EU curve published in the EU position paper on noise annoyance (European Commission, 2002) but is shifted toward the left by about 5 to $10 \mathrm{~dB}$, indicating that the percentage of highly annoyed persons is actually higher than would be predicted by the EU curve. The current data provide additional evidence that annoyance has increased in the past decades and that aircraft noise annoyance of residents in Europe (and probably elsewhere too) nowadays no longer seems to be well reflected in the EU curve, confirming other recent findings from the UK, Germany, The Netherlands, Greece, Spain, and Italy (Babisch et al., 2007; Breugelmans et al., 2004; Department for Transport, 2007; Schreckenberg and Meis, 2006). Furthermore, we could not determine any threshold exposure value below which \%HA would be zero. That means that the feeling of being highly annoyed by aircraft noise in our sample was not necessarily bound to acoustic exposure at all.

Respondents in our study are slightly less annoyedespecially at exposure values above about $50 \mathrm{~dB}(\mathrm{~A})$ $L_{\mathrm{dn}}$ - than in comparable recent European studies such as from Amsterdam 2002 (Breugelmans et al., 2005) or Frankfurt 2005 (Schreckenberg and Meis, 2006). A possible explanation for this difference could be the smaller number of aircraft operations in Zurich, as compared to large European hub airports that are particularly often in the focus of annoyance studies (London Heathrow, Amsterdam, and Frankfurt). An alternative explanation would also be that the observed differences in annoyance are an effect of exposure calculation differences of the different aircraft noise models used in the respective studies. As it has been mentioned, the Swiss calculation model FLULA2 is suspected to yield somewhat higher exposure estimates at calculated levels below $55 \mathrm{~dB}(\mathrm{~A})$ as, e.g., the INM. In this light, the comparison between the Zurich data and the EU curve in Fig. 1 might be interpreted with caution also. However, only a systematical error analysis that accounts for uncertainty of the calculated levels and uncertainty of the parameters of the exposureeffect model could clarify this issue.

\section{Influence of an exposure change on annoyance}

In the past, several authors emphasized the importance of evaluating noise effects due to changes in exposure (Fidell et al., 2002; Fields et al., 2000; Guski, 2003; Guski, 2004; Horonjeff and Robert, 1997; Job, 1988a; Krog and Engdahl, 2004). The study we reported about was to a certain degree comparable to the step change investigation carried out at Vancouver International Airport (Fidell et al., 2002) but is characterized by a different approach to data analysis. For the forecasting of noise annoyance after operational changes, the ability to predict the annoyance shift as a function of the amount of change is very useful. Mainly for reasons of usability, we describe a model that operationalizes the change as a decibel difference value on a continuous scale reaching 
from a negative difference (decrease of exposure) to a positive one (increase of exposure). Although tiny increases or decreases of $L_{A \text { eq }}$ values might not be perceivable on an individual level, we could supply evidence that previously experienced exposure change significantly shifts the exposureannoyance relationship of residents-at least for several months. Therefore, it seems justified to promote a model that incorporates that change and expresses it in a manner that airport authorities or communal agencies can handle, namely, decibel values and decibel differences. In contrast to generalized exposure-effect curves, which do not account for change effects, the models (a) and (b) in Table III use both the current exposure and the change of exposure as predictors of high annoyance. Therefore, they provide a useful addition to other exposure-effect models in the literature (e.g., the ones from Miedema and Vos, 1998). Because in the current case, the operational change at Zurich Airport was limited to the early morning and the late evening hours, we calculated two separate models, one for the impact of the change in the evening, and one for the impact of the change in the early morning. From the data that were available to us, we could not draw any conclusions pertaining to the effects of an overall general step change that affects the whole day or night period (e.g., opening of an entirely new airport)

The aircraft noise situation that prevailed during the study period can be described as a series of distinctive changes within a period of roughly one and a half years, whereas the last step that took place after April 17, 2003 (Installation of ILS) was particularly large. The following four to five months before the second survey obviously were not long enough a period for the over-reaction effect to diminish, supporting the assumption that the duration of overreaction effects is rather a question of months or years than days or weeks.

The average exposure in the year 2003, which was the basis for the exposure difference calculations, was affected by two major operational changes: After April 17, 2003, a large part of inbound shoulder hour flights previously using another runway were relocated to use Runway 28 for landing. The landing regime was changed again after October 30, 2003, after the second survey: Inbound flights in the early morning now used Runway 34 and approached the airport from the south (see grayscale gradient in Fig. 3), releasing the east from the early morning noise burden. Therefore, the reported morning exposure as well as its changes are somewhat smaller than the average exposure that prevailed during the five months before the second survey (AugustSeptember 2003) in the eastern communities. Thus the estimation of the change effect as pertaining the morning shoulder hours can be termed rather conservative.

It has been hypothesized (Fidell et al., 1985; Van Kempen and Van Kamp, 2005) that public awareness or the expectancy of an upcoming change alone may be enough to evoke an advanced over-reaction so that higher-thanpredicted annoyance would be reported by respondents even before an exposure change actually takes place. Although the upcoming changes in the flight regime were announced in the media for more than a year in advance, we found no evidence that the eastern residents prematurely "reacted" to the future noise situation. If that would have been the case, a probably much smaller difference of high annoyance or no difference at all during shoulder hours would have been found between 2001 and 2003 in this population group. Therefore, we conclude that residents actually rate their annoyance based on real experienced exposure and not on any imaginary future noise scenario. This conclusion is further supported by the fact that we could not find any statistical evidence that the year of survey had an independent effect on the probability of high annoyance in the whole sample despite the fact that the aircraft noise issue in 2003 was much more intense a matter of public debate than in 2001.

\section{ACKNOWLEDGMENTS}

This study was funded by the Swiss Federal Office for the Environment, the Swiss Federal Office of Public Health and Unique Flughafen Zürich AG. We are grateful to these institutions for their financial support. We would further like to thank Joachim Kastka, Tommaso Meloni, Walter Krebs, Philipp Huber, Helmut Krueger, Tommy Läubli, HansRudolf Roth, and Werner Stahel who contributed to improving the study design, to data collection and processing, and data analysis. All authors declare no conflicts of interest regarding the work presented in this article.

Arbeitsgemeinschaft für sozio-psychologische Fluglärmuntersuchungen. (1974). "Soziopsychologische Fluglärmuntersuchung im Gebiet der drei Schweizer Flughäfen Zürich, Genf, Basel (Socio-psychological investigation of aircraft noise around the tree Swiss airports Zurich, Geneva, Basel)," Eidgenössisches Luftamt, Bern.

Babisch, W., Houthuijs, D., Pershagen, G., Cadum, E., Velonakis, M., Katsouyanni, K., and Jarup, L. (2007). "Associations between road traffic noise, aircraft noise and noise annoyance. Preliminary results of the HYENA study," Paper presented at the 19th International Congress on Acoustics ICA, Madrid, Spain.

Beck, U. (1992). Risk society: Towards a New Modernity (Sage, London). Berglund, B., and Lindvall, T. (1995). "Community noise," Archives of the Centre for Sensory Research (Stockholm University and Karolinska Institute, Stockholm), Vol. 1, No. 1.

Breugelmans, O. R. P., van Wiechen, C. M. A. G., van Kamp, I., Heisterkamp, S. H., and Houthuijs, D. J. M. (2004). "Gezondheid en beleving van de omgevingskwaliteit in de regio Schiphol: 2002 [RIVM rapport 630100001/2004] (Health and quality of life near Amsterdam Schiphol Airport: 2002 Interim report [RIVM report 630100001/2004])," avaliable at: http://www rivm.nl/bibliotheek/rapporten/630100001.pdf (last viewed on $01 / 16 / 2008$ )

Brink, M., Thomann, G., Huber, P., and Schierz, C. (2007). "A new noise impact assessment method for noise policy," Paper presented at the Internoise 2007, Istanbul, Turkey.

Bröer, C. (2007). "Aircraft noise and risk politics," Health Risk Soc. 9, $37-52$.

Bröer, C., and Wirth, K. (2004). "Mehr Belästigung bei gleichem Pegel. Wieso Flugzeuggeräusche heute möglicherweise lästiger sind als vor 40 Jahren (More annoyance at identical levels. Why aircraft sounds may be more annoying today than 40 years ago)," Zeitschrift für Lärmbekämpfung 51, 118-121.

Department for Transport. (2007). "Attitudes to Noise from Aviation Sources in England (ANASE) Final Report," avaliable at http:// www.dft.gov.uk/pgr/aviation/environmentalissues/Anase/ (last viewed on 06/12/2008).

European Commission. (2002). "Position paper on dose response relationships between transportation noise and annoyance," avaliable at http:// ec.europa.eu/environment/noise/pdf/noise_expert_network.pdf (last viewed on 01/16/2008).

European Union. (2000). "Proposal for a European Parliament and Council Directive on the Approximation of the Laws of the Member States Relat- 
ing to the Assessment and Reduction of Environmental Noise," EU, Brussels.

Fidell, S., Barber, D. S., and Schultz, T. J. (1991). "Updating a Dosage Effect Relationship for the Prevalence of Annoyance Due to General Transportation Noise," J. Acoust. Soc. Am. 89, 221-233.

Fidell, S., Horonjeff, R., Mills, J., Baldwin, E., Teffeteller, S., and Pearsons, K. (1985). "Aircraft noise annoyance at three joint air carrier and general aviation airports," J. Acoust. Soc. Am. 77, 1054-1068.

Fidell, S., Silvati, L., and Haboly, E. (2002). "Social survey of community response to a step change in aircraft noise exposure," J. Acoust. Soc. Am. 111, 200-209.

Fields, J. M., De Jong, R. G., Gjestland, T., Flindell, I. H., Job, R. F. S., Kurra, S., Lercher, P., Vallet, M., Yano, T., Guski, R., Felscher-Suhr, U., and Schumer, R. (2001). "Standardized general-purpose noise reaction questions for community noise surveys: Research and a recommendation," J. Sound Vib. 242, 641-679.

Fields, J. M., Ehrlich, G. E., and Zador, P. (2000). "Theory and design tools for studies of reactions to abrupt changes in noise exposure [NASA Contractor Report No. CR-2000-210280]," Hampton, VA: NASA Langley Research Center.

Griffiths, I. D., and Raw, G. J. (1989). "Adaptation to changes in traffic noise exposure," J. Sound Vib. 132, 331-336.

Guski, R. (2001). "Der Referenten-Entwurf zum Fluglärmgesetz aus der Sicht eines Wirkungsforschers ("The draft bill of aircraft noise regulation as seen by a noise effects researcher")," Zeitschrift für Lärmbekämpfung 48, 130-131.

Guski, R. (2003). "How to predict future annoyance in planning?" Proceedings of the Eighth International Congress on Biological Effects of Noise ICBEN Rotterdam, The Netherlands, pp. 255-256.

Guski, R. (2004). "How to forecast community annoyance in planning noisy facilities," Noise Health 6, 59-64.

Horonjeff, R. D., and Robert, W. E. (1997). "Attitudinal responses to changes in noise exposure in residential communities (Report number: HMMH-293350, NAS 1.26:205813, NASACR-1997-205813)," Hampton, VA: National Aeronautics and Space Administration (NASA) Langley Research Center.

Job, R. F. S. (1988a). "Community response to noise: A review of factors influencing the relationship between noise exposure and reaction," J. Acoust. Soc. Am. 83, 991-1001.

Job, R. F. S. (1988b). "Overreaction to Changes in Noise Exposure-the Possible Effect of Attitude," J. Sound Vib. 126, 550-552.
Job, R. F. S., and Hatfield, J. (2003). "A model of responses to changes in noise exposure," Proceedings of the Eighth International Congress on Biological Effects of Noise ICBEN Rotterdam, The Netherlands , pp. 232234.

Krebs, W., Bütikofer, R., Plüss, S., and Thomann, G. (2004). "Sound source data for aircraft noise simulation," Acta. Acust. Acust. 90, 91-100.

Krog, N. H., and Engdahl, B. (2004). "Annoyance with aircraft noise in local recreational areas, contingent on changes in exposure and other context variables," J. Acoust. Soc. Am. 116, 323-333.

Miedema, H., and Oudshoorn, C. (2001). "Annoyance from transportation noise: Relationships with exposure metrics DNL and DENL and their confidence intervals," Environ. Health Perspect. 109, 409-416.

Miedema, H., and Vos, H. (1998). "Exposure-response relationships for transportation noise," J. Acoust. Soc. Am. 104, 3432-3445.

Oliva, C. (1998). "Belastungen der Bevölkerung durch Flug- und Strassenlärm (People's exposure to aircraft and road traffic noise)," (Duncker\&Humblot, Berlin).

Olmstead, J. R., Fleming, J. M., and Gulding, J. M. (2001). "Integrated Noise Model (INM), Version 6.0, Technical Manual [Report No FAAAEE-02-01]," Federal Aviation Administration (FAA), Department of Tranportation, Washington DC.

Pietrzko, S. J., and Hofmann, R. F. (1988). "Prediction of A-Weighted Aircraft Noise Based on Measured Directivity Patterns," Appl. Acoust. 23, 29-44.

Raw, G. J., and Griffiths, I. D. (1990). "Subjective response to changes in road traffic noise: A model," J. Sound Vib. 141, 43-54.

Schreckenberg, D., and Meis, M. (2006). "Effects of aircraft noise on noise annoyance and quality of life around Frankfurt Airport. Final abbridged report," avaliable at http://www.verkehrslaermwirkung.de/FRA070222.pdf (last viewed on 03/15/2008).

Schultz, T. J. (1978). "Synthesis of social surveys on noise annoyance," J. Acoust. Soc. Am. 64, 377-405.

Thomann, G. (2007). "Mess- und Berechnungsunsicherheit von Fluglärmbelastungen und ihre Konsequenzen (Uncertainties of measured and calculated aircraft noise and consequences in relation to noise limits) $[\mathrm{PhD}$ thesis, ETH Zurich]," avaliable at http://e-collection.ethbib.ethz.ch/ show?type $=$ diss\&nr $=17433$ (last viewed on 3/20/2008).

van Kempen, E. E., and van Kamp, I. (2005). "Annoyance from air traffic noise. Possible trends in exposure-response relationships [Report No 01/ 2005 MGO EvK]," Dutch Ministry of Housing and Environmental and Spatial Planning, Bilthoven. 